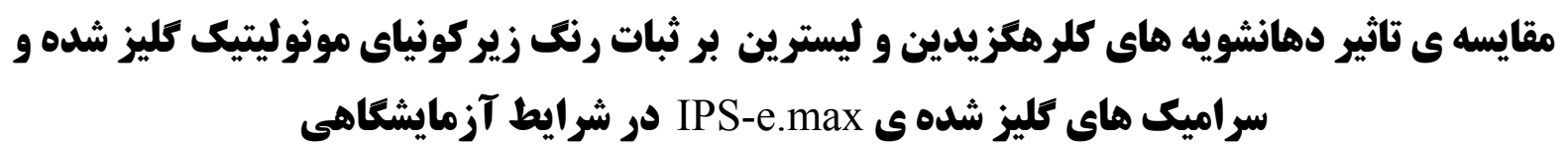

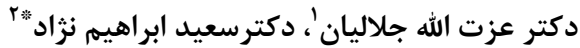

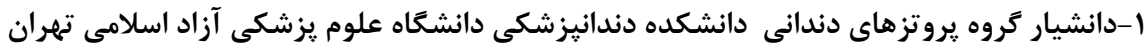

$$
\begin{aligned}
& \text { ז-دندانيزشك }
\end{aligned}
$$

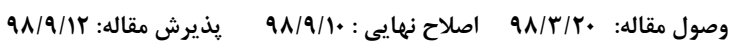

\title{
Comparison of the effect of chlorhexidine and listerine on the stability of the monolithic glazed zirconium dye and the IPS-e.max glazed ceramics( in vitro)
}

\author{
Jalalian EZ ${ }^{1}$,Saeid Ebrahimnejad ${ }^{2}$ \\ ${ }^{1}$ Associate Prof, Department of Prosthodontics, Faculty of Dentistry, Tehran Medical Sciences, Islamic Azad University, Tehran, Iran. \\ ${ }^{2}$ Dentist
}

Received: June 2019

; Accepted: Dec2019

\section{Abstract}

Background and aim: Regarding the prevalence of monolithic zirconia and glazed ceramics IPS-e.max, and inadequate research on the color change of chlorhexidine and listerine mouthwashes on these two types, this study was aimed to compare the effect of these two mouthwashes on the stability of the The mentioned materials.

Materials and Methods: This experimental study was carried out in vitro. 38 samples of monolithic zirconia and glazed ceramics IPS-e.max were prepared. The primary color was measured by spectrophotometry. The samples were randomly assigned to chlorhexidine, listerine and water mouthwashes. Developments for 7 days, every 2 minutes, in chlorhexidine $0 / 00.2 \%$, Listerine Zero Then the secondary color was again measured by spectrophotometry and (4) $\Delta \mathrm{E}$ ab were evaluated by Kruskal Wallis test.

Results: Both types of ceramics after the immersion in two types of mouthwash and distilled water were changed as control. $\Delta \mathrm{E}$ values of the two substance after being placed in chlorhexidine (Monolithic zirconium $(\Delta \mathrm{E}=0.16 \pm 0.11)$ and glazed ceramics IPS-e.max $(\Delta \mathrm{E}=0.39 \pm 0.14)$ showed a significant difference compared to the initial colorimetry $(\mathrm{P}<0.001)$.Also, the amounts of $\Delta \mathrm{E}$, two substances after placement in Listerine (monolithic zirconium $(\Delta \mathrm{E}=0.26 \pm 0.17)$ and glazed ceramics IPS-e.max $(\Delta \mathrm{E}=0.48 \pm 0.29)$ compared to colorimetric Primary difference was not significant $(\mathrm{p}<0.06)$. Kruskal Wallis test showed that this difference $\Delta \mathrm{E}$ was significant between the four groups $(\mathrm{p}<0.02)$.

Conclusion: The color consistency of both monolithic zirconium and Ips.emax ceramics seems to be clinically acceptable.

Keywords : Mouthwashes,Chlorhexidine, Ceramic, Zirconia, Spectrophotometry

*Corresponding Author: Saeed.e.math@gmail.com

J Res Dent Sci. 2019; 16(4): 260-7 
خلاصه:

سابقه وهدف: با توجه به شايع بودن تغيير رنگ zirconia monolithic و سراميكهاى كليز شده IPS-e.max و تحقيقات ناكافى

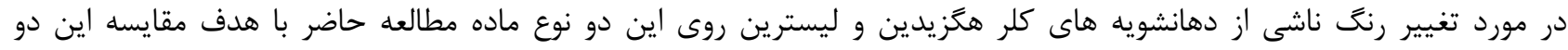
دهانشويه بر رنغ مواد مذكور انجام شد.

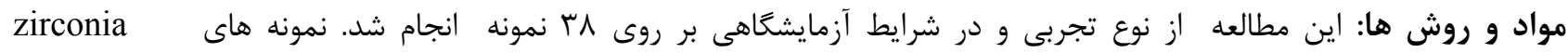

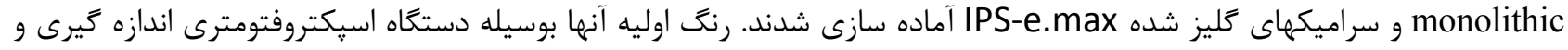

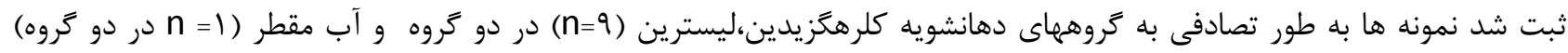

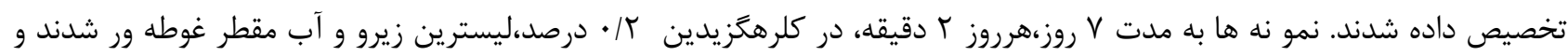

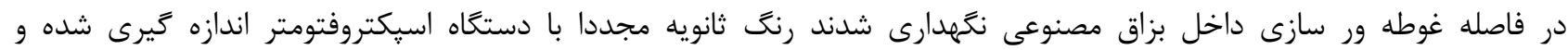

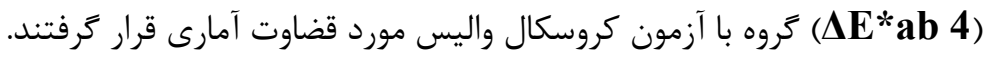

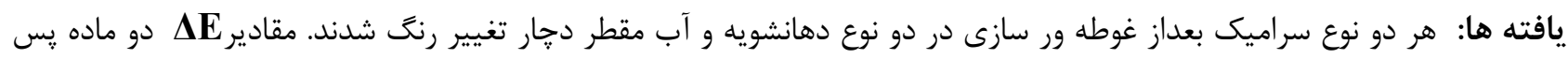

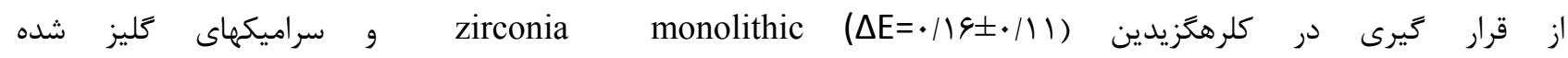

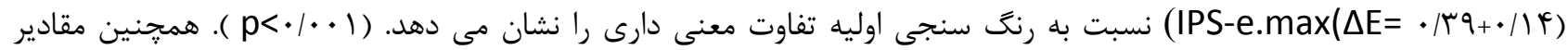

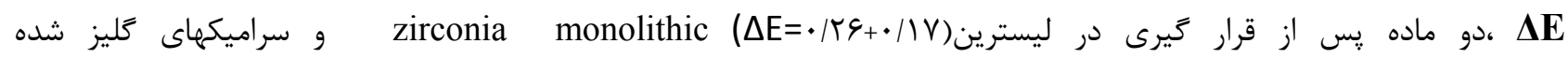

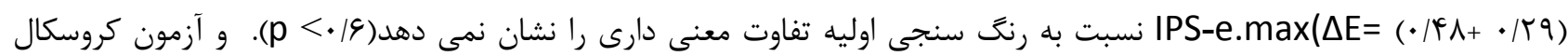
واليس نشان داد كه اين تفاوت EE

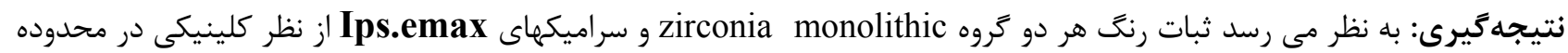
قابل قبول بود. كليد وازه ها: دهانشويه ، كلرهكَ يدين، سراميك، زير كونيا، ، اسيكتروفتومترى

مقدمه:

باشد و معمولاً اين دهانشويه ها براى جلوكيرى از عفونت بعد از جراحى دهان •يرى ايميلنتايتيس و موارد مشابه) تجويز مىشوند كه در مطالعات بيشين كلر هكَزيدين در مقايسه با ديكر دهانشويه ها داراى كمترين ميزان تاثير روى تغيير رنگ سراميك ها بوده است و تاثير بسزايى در كنترل رشد باكتريها دارد.

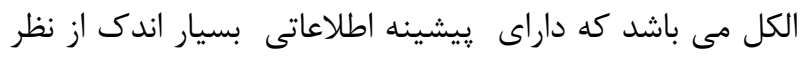

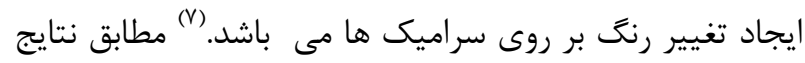

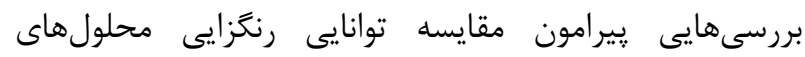

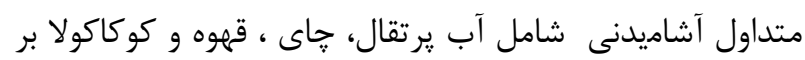

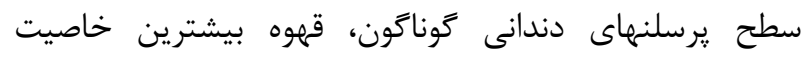

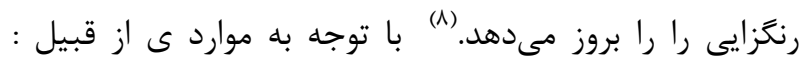

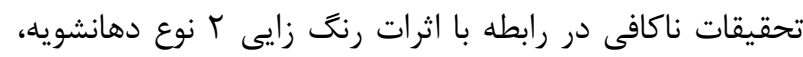
مدت نسبتاً طولانى استفاده از روكش هاى دندانى و و تمايل روز افزون بيماران جهت زيبايى دندانهايشان و عدم بررسى تاثير
مواد سراميكى به واسطه فوايدشان از جمله سازكارى بيولوزيكى، طول عمر بالا، استحكام و قابليتهاى بسيار مطلوب

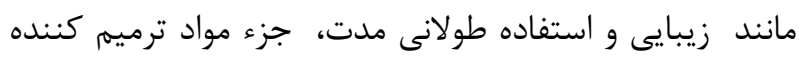

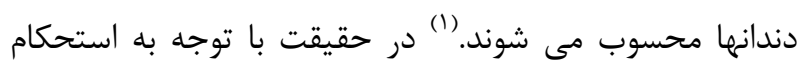

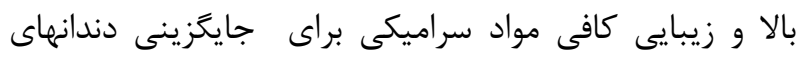
قدامى و خلفى انتخاب مناسبى هستند .تغيير رنى رستوريشن به مرور زمان خالشى است كه زيبايى ظاهرى را به خطر مى مىاندازد. برداشت پٍاك به دو روش مكانيكى و شيميايى انجام مى شود،

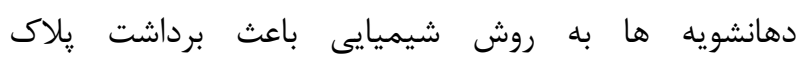

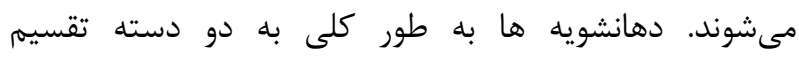

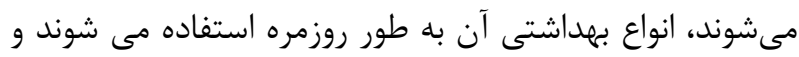
انواع ديكر دهانشويه درمانى نام دارند كه به محافظت در برابر

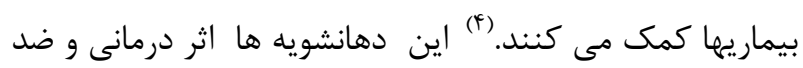

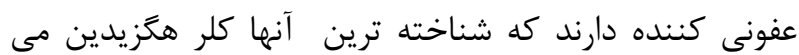




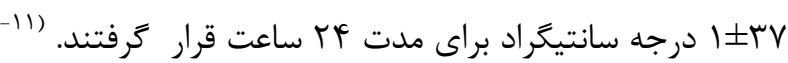

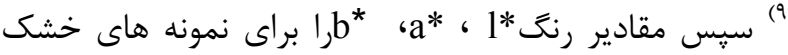
شده در همه گروه ها به عنوان مقادير اوليه اندازه گرفتيم كه

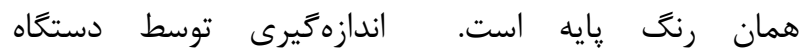

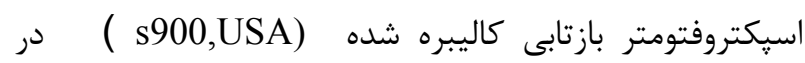
دانشكده دندانيزشكى شهيد بهشتى و در برابر زمينه سفيد انجام شد كه يرتوها عمود بر سطوح نخه داشته شده و شرايطى مشابه براى تمام نمونه ها فراهم شده بود. تمام اندازه كيرى ها تحت يك منبع نور D56 و محدوده طول موج ·VA •مץ نانومتر مشاهده و انجام شد. ديسك هاى آماده شده را به مدت FF Tاعت در آب مقطرو در دماى WV درجه سانتيگراد نكَهدارى و سيس هر بصورت تصادفى به ץ زيركروه تقسيم شدند. زيركروه اول از هردو زروه A,B در دهانشويه

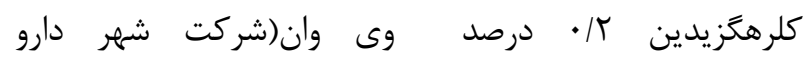
تهران،ايران، يايه غير الكلى) با PH=5.1 و Prس درجه سانتيگراد. و زير گروه دوم از هردو گروه A,B در دهانشويه ليسترين زيرو(شركت راس درمان .ايتاليا.فاقد الكل) با 4.2 ودماى V درجه سانتيگراد و گروه هاى كنترل (تعداد =|) را در آب مقطر(شركت كيميا. تهران) به مدت r دقيقه، يكبار در روز و به مدت V روز تكرار شد. و در اين هفت روز آب مقطر با آب مقطر جديد جايگزين گرديد. در فواصل بين غوطه ورسازى نمونه ها در دهانشويه ها، نمونه ها در بزاق مصنوعى قرار داده شد و بزاق به طور روزانه با بزاق جديد جايگزين گرديد و اندازهيرى نمونهها بعداز V روز انجام شد. پس از خشك شدن نمونه ها شاخص هاى رنگ ثانويه (b,a,l)توسط دستخاه

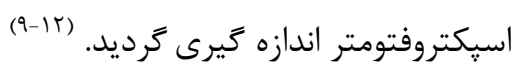

سيس داده ها در فرم اطلاعاتى ثبت شد.تغيير رنت

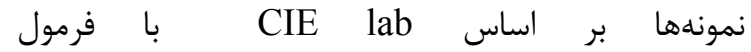
هE $\Delta \mathrm{E}=\sqrt{ }\left((\Delta L)^{\wedge} 2+(\Delta a)^{\wedge} 2+(\Delta b)^{\wedge} 2\right)$

اطلاعات نمونه ها براى تعيين تغيير رنغ با آزمون داده مى شود و آناليز كل داده ها Two -Way- ANOVA توسط آزمون كروسكال واليس محاسبه شد.
اين دهانشويهها بر روى زيركونيا ،اين تحقيق با هدف بررسى مقايسهى تاثير r دهانشويه كلر هگزيدين و ليسترين زيرو (فاقد الكل ) برورى ثبات رنت zirconia monolithic سراميكهاى كليز شده ى IPS-e.MAX در دانشكده

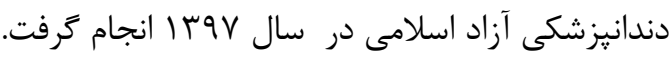

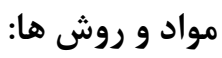

اين يزوهش از نوع تجربى بوده و در شرايط آزمايشعاهى انجام شد.

جهت مطالعه ^ץ نمونه ديسك بصورت زير تهيه شد كه Fروه A شامل ديسك هايى به قطر · اميلى متر و ضخامت:

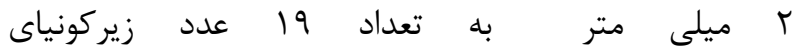
monolithic (aman Gilbakh-Germany, Austria) CAD/CAM ( aman Gilbakh-Germay, Austria ) دستعاه در تهران آماده شد و بعداز غوطه ور سازى در نمونه رنت بوسله يك لايه نازى از خمير كليز IPS-e.max ceram ) glaze; Ivocolor vivadent-) ((Austromat 3001;Dekema dental- keramikGermany

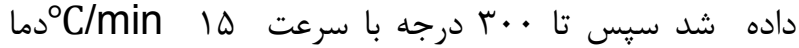

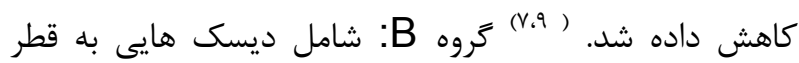
m و ضخامت rmm 1. IPS-e.max ceram (Ivocolor vivadent-Germany) شكل قرص از اينگات هاى A2 يس از تهيه توسط سيستم Press (Germany- Ivocolor vivadent) (IPS-e.max ceram glaze; توسط لايه نازك از خمير كليز Iايوشيده شده و در كوره خلا ((Austromat 3001;Dekema dental- keramikGermany

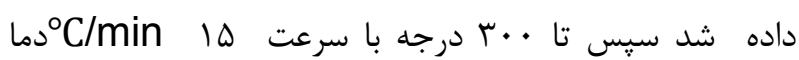

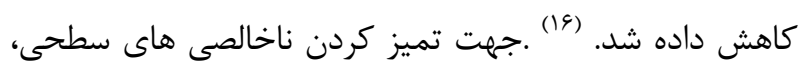
نمونه ها با آب مقطر شسته شدند و يروسه اتوگليز انجام گرفت. قبل از اندازه گيرى رنگ اوليه، نمونه ها در آب مقطر در دماى 
تاثير ليسترين روى تغيير رنگ Zirconia Monolitic و سراميك هاى تليز شده Ips.E max:

ميزان Zirconia Monolitic در كروه

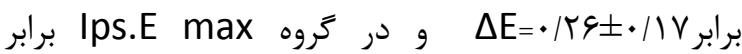
$\Delta E=\cdot / \kappa \lambda \pm \cdot / r q$ آمارى معنى دار نيست. (P< (P) مقايسه تاثير كلرهگزيدين و ليسترين روى تغيير رنغ Zirconia Monolitic

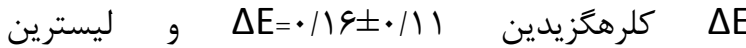
$\Delta \mathrm{E}=\cdot / \kappa \varepsilon \pm \cdot / \mid V$

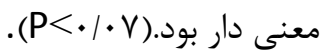
مقايسه تاثير كلرهخزيدين و ليسترين روى تغيير رنخ

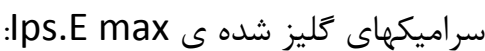
كلرهكزيدين $\Delta \mathrm{E}$ $\Delta \mathrm{E}=\cdot / \mathcal{F} \lambda \pm / r q$

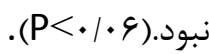
در يك مقايسه ب كروه كمترين تغييرات DE مربوط به كلرهكزيدين با Zirconia Monolitic و بيشترين مربوط به ليسترين روى ماده Ips.E max بود.آزمون كروسكال واليس نشان داد كه اين تغيير رنگ در جهار كروه به لحاظ آمارى

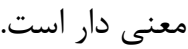

دهانشويه ها و بزاق مصنوعى استفاده شده در اين يزوهش

\begin{tabular}{|c|c|c|c|}
\hline PH & تركيبات & كشور سازنده & دهانشويه وبزاق \\
\hline$\Delta / 1$ & 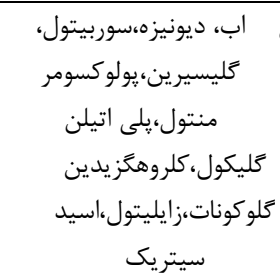 & شهر داروتتهران & كلر هَّزيدين \\
\hline$F / T$ & 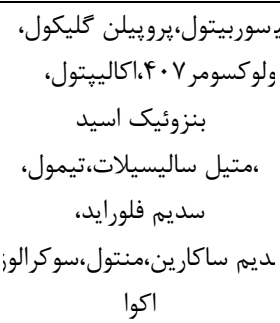 & إس درمان،ايتالي. & ليسترين \\
\hline S/NA & 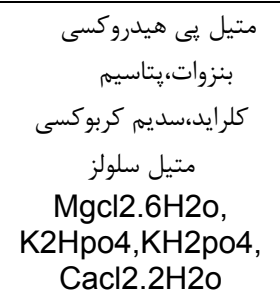 & رويعت،ايران & بزاق مصنوعى \\
\hline
\end{tabular}

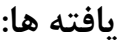

Zirconia تحقيق روى ^ץ نمونه ديسك شامل دو ماده Monolitic دوكروه كلرهكَيدين و ليسترين كه هركدام در دو زيركروه 9 نمونه اى انجام كرفت ،رنگ اوليه ،ثانويه و كروهها در جدول r ارائه شد و نشان مى دهد كد: تاثير كلرهكَيدين روى تغيير رنى سراميك هاى كليز شده Ips.E max به شرح زير است:

Zirconia Monolitic ميزان

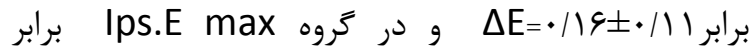

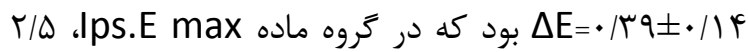
برابر بيشتر بوده و اين به لحاظ آمارى معنى دار بود. $(\mathrm{P}<\cdot / \cdot \cdot 1)$ 


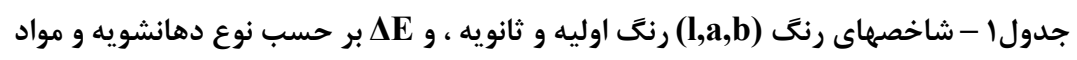

ثانويه

اوليه

\begin{tabular}{|c|c|c|c|c|c|c|c|c|c|}
\hline & & & ثانويه & & & اوليه & & & \\
\hline & $\Delta \mathrm{E}$ & $\mathrm{L}$ & $\mathrm{b}$ & $\mathrm{a}$ & 1 & $\mathrm{~b}$ & $\mathrm{a}$ & & نوع ماده \\
\hline \multirow[t]{2}{*}{$\mathrm{P}<\bullet / \cdots)$} & $\cdot / 19 \pm \cdot / 11$ & $\vee \xi / 1 r \pm \cdot / 9 \Delta$ & $19 / V 9 \pm \cdot / V$ & T/r \pm •// & $\vee ९ / 1 \pm \cdot / 99$ & 19/VG & T/r $\pm \cdot / \cdot 9$ & $\begin{array}{l}\text { Zirconia } \\
\text { Monolitic }\end{array}$ & \multirow{2}{*}{$\begin{array}{c}\text { كلرهًز يدين } \\
\text { n=9 } \\
\text { n=9 }\end{array}$} \\
\hline & $\cdot / r q \pm \cdot / / 4$ & 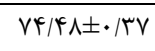 & $19 / 99 \pm \cdot / \Upsilon \wedge$ & $r / r \pm \cdot / / \Delta$ & $V * / \mu 1 \pm \cdot / \mu r$ & $\mid q / 8 \wedge \pm \cdot / 4 \wedge$ & $1 / 91 \pm \cdot / 19$ & Ips.Emax & \\
\hline \multirow[t]{2}{*}{$\mathrm{P}<\cdot / 7$} & $\cdot / r \xi \pm \cdot / / V$ & $V \Delta / \cdot r \pm \cdot / F r$ & $19 / 1 \wedge \pm \cdot / 4$ & $r / r \mid \pm \cdot / \cdot V$ & $V \varphi / q r \pm \cdot / \cdot q$ & $19 / / r \pm \cdot / q V$ & $r / / 9 \pm \cdot / / T$ & $\begin{array}{l}\text { Zirconia } \\
\text { Monolitic }\end{array}$ & \multirow{2}{*}{ 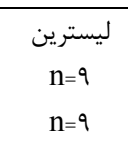 } \\
\hline & $\cdot / \uparrow \wedge \pm \cdot / \kappa q$ & $V F / \Lambda r \pm \cdot / \mathcal{F} r$ & $|V /| f \pm \cdot / r$ & 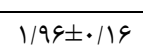 & $V F / \Delta T \pm \cdot / \varphi$ & $\mid V / \cdot r \pm \cdot / r r$ & $1 / 9 r \pm \cdot / 10$ & $\overline{\text { Ips.Emax }}$ & \\
\hline
\end{tabular}

يكى از عوامل مهم در تعيين موفقيت رستوريشن هاى

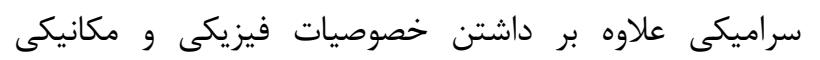

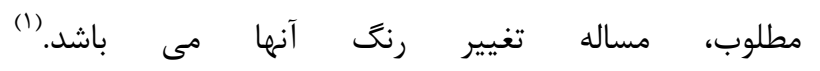

Preshede مى تواند به دو صورت zirconia monolithic و ساخته شود. طبق نتايج تحقيقات متعدد مبنى ير اينكه رنگ زيركونيا هموزن و ثبات تر از انواع externally shade است. در اين تحقيق از مبند

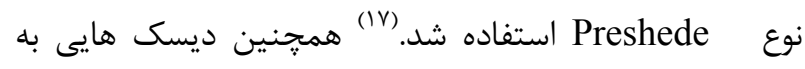
قطر • اميلى متر و ضخامت كميلى متر به تعداد 19 نمونه

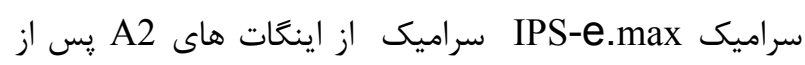

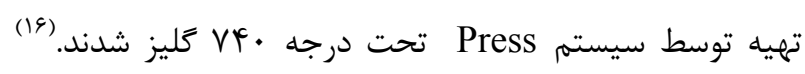

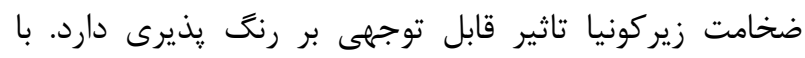

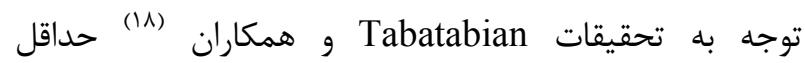

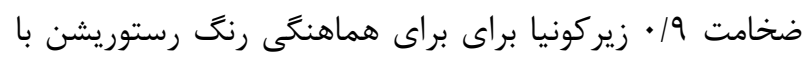

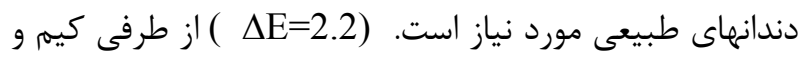

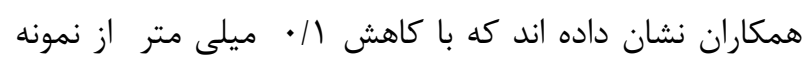

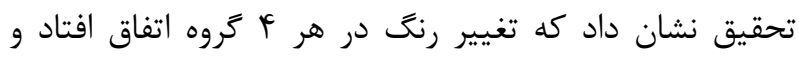

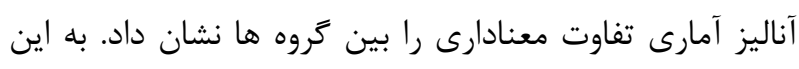
ترتيب فرضيه تحقيق مبنى بر اينكه دهانشويه ها مى توانند در

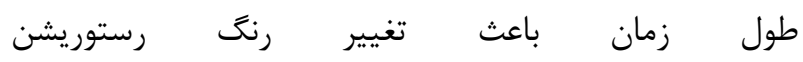
هاى zirconia monolithic و سراميك تهيك شده بشوند، تاييد شد.در اين يزوهش ديسك هايى به

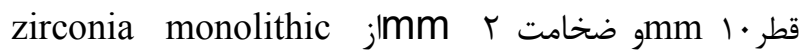
بعداز ساخت و sintering و غوطه ور سازى در نمونه رنگ

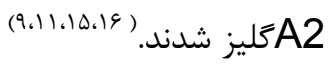
دليل انتخاب zirconia monolithic محبوبيت اين رستوريشن در سالمهاى اخير و دارا بودن استحكام خمشى بالا ،

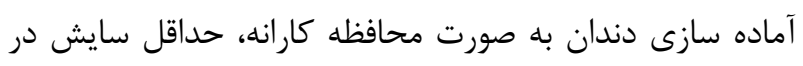
دندان هاى مقابل، كاهش زمان لابراتوارى و كلينيكى آن و عدان مدان

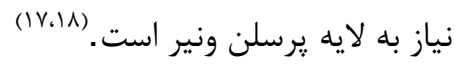


palla و همكارانش در يونان تحقيقى تحت عنوان ثبات رنغ

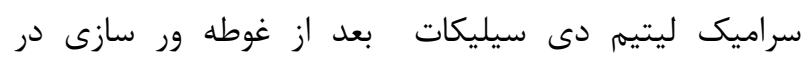

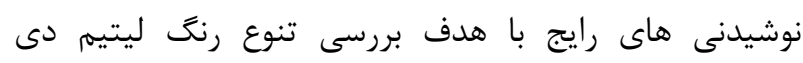

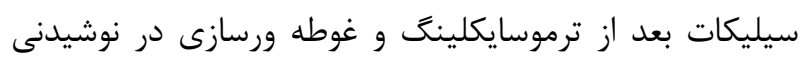
هايى كه به طور معمول مصرف مى شود ارائه دادند. .نتايج

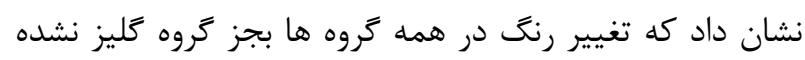
در جاى در محدوده قابل قبول كلينيكى است. بيشتر بودن ميزان DE در اين تحقيق در مقايسه با تحقيق حاضر مى تواند هم بدليل تفاوت در نوع سراميك و همجنين كَليز نشدن سطح

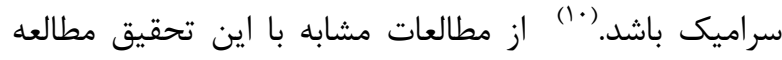
Khaledi

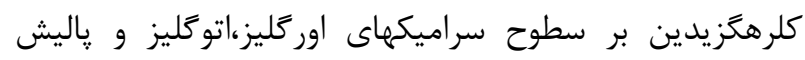

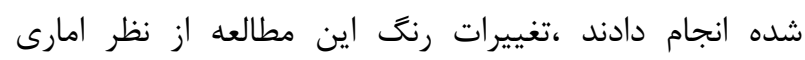

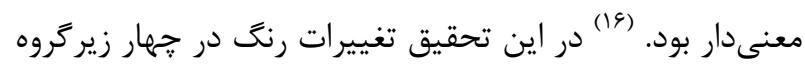

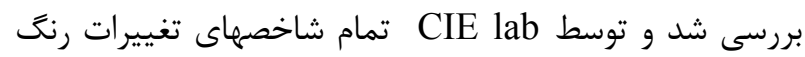
اوليه و ثانويه a,b,1 و L و اله به طور كامل محاسبه كرديم. تغييرات رنغ مواد را بر اساس آزمون كروسكال واليس كه

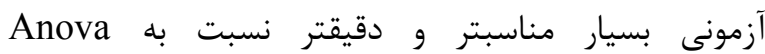

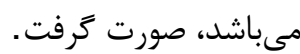
Eslami هاى مختلف حاوى ذرات نانو بر ميناى دندان انجام دادند.

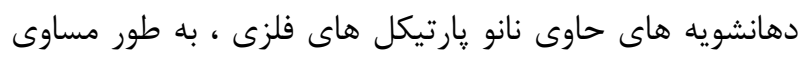

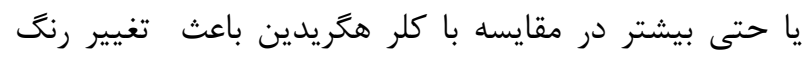

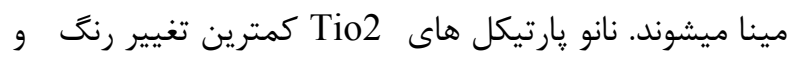
Zno

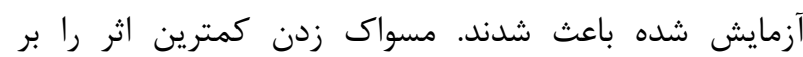

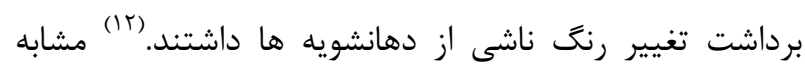
بودن اين مطالعه با تحقيق ما در اين است كه دهانشويه كلرهكَيدين تغيير رنغ كمترى بر مواد دارد. Lavaf و همكاران مطالعه ى به منظور اثر سه نه نوع دهرير دهانشويه

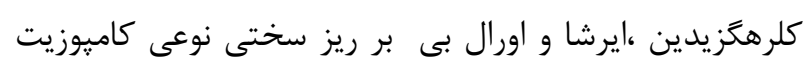

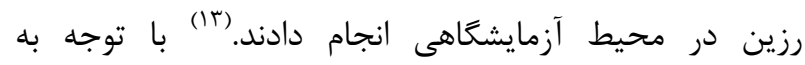

زيركونياى Y ميلى مترى تغيير رنغ قابل توجهى در رستوريشن ايجاد شد . ( ها با ضخامت آميلى متر تهيه شدند كه اين ضخامت قابل مقايسه با شرايط كلينيكى مىباشد. (1) در تحقيقات براى اندازه

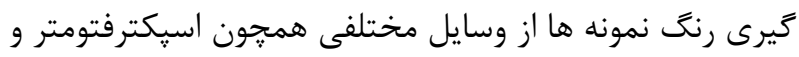
كالريمتر، اسيكتروراديومتر و دوربين ديجيتال استفاده شده است. با توجه به اينكه اسيكترومتر انرزى نور منعكس شده را به صورت عددى كزارش مى كند آسان تر و دقيق تر از ساير دستكاه ها بوده و ما در اين تحقيق از اسيكترومتر استفاده كرديم. داده هاى حاصل از اين دستگاه مقادير شاخص هاى

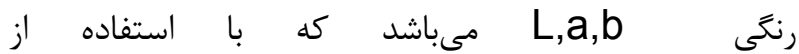
فرمول $\Delta \mathrm{D}$ Dاسبه شد. در تحقيقات براى آناليز تغييرات رنح از سيستم CIElab استفاده مى شود كه منجر به شناسايى هر نوع تفاوت رنغَ كوجى بين نمونه ها شده و به صورت كَترده

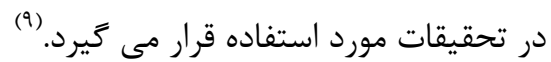
Derafshi بررسى تاثير دهانشويه هاى كلرهكزيدين و ليسترين بر ثبات رنغ زيركونى zirconia monolithic و سراميكهاى Feldspathic تغييرات رنغ دو ماده zirconia monolithic و يرسلن فلد دئ دان سياتيك در اثر غوطه ورسازى در دو نوع دهانشويه كلر

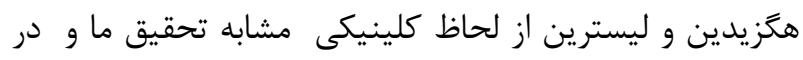

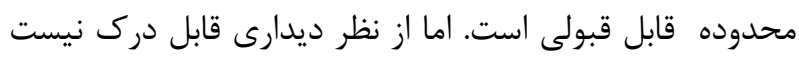

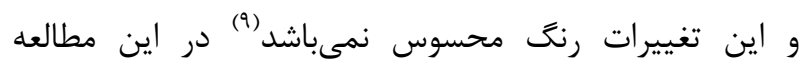
بيشترين تغييرات رنخ مربوط به كلر هكزيدين بود و اين با فيا مطالعه ما كه بيشترين تغيير رنخ را مربوط به ليسترين مىداند مغاير دارد. (البته تغييرات بسيار محسوس نيست) و احتمالا بخاطر دفعات بيشتر اندازه گيرى رنگ ثانويه توسط دستگاه اسيكتروفتومتر در اين تحقيق نسبت به تحقيق ما مى باشد، كه باعث شد، دقت اندازه كيرى بالاتر رود. 


\section{References:}

1.SaikayaI,Guler AU,Effects of different surface treatments on the color stability of varios dental porcelains.journal of dental sciences $2011 ; 6(2): 65-7$

2.Koksal T,Dikbas I. Color stability of different teeth materials against various staining agents. Dent Mater $\mathrm{j}$ 2008;27(1) :139-44

3.Tork zaban P, Kadkhoda M. Investigating the effect of sequential use of chlorhexidine and sodium fluoride mouthwashes on microbial plaque control. Journal of Shahid Beheshti Dental school 2015;29(3):394-400.

4.Memarian J, Nasirian S, Farhad Sh, Esfahanian . Comparison of Clinical Effects of Two Iranian and Foreign Mouthwashes containing Chlorhexidine and Sodium Fluoride on Dental Plaque Removal.Journal of Isfahan Dental school 2015;12(1):46-53.

5.Patel A, Sethuraman R, Prajapati P, Patel J, Naveen YG. A comparative analaysis of staining characteeris of mouthrinses on provisional acrylic resin : an in vitro study. J Interdiscip Dentistry 2013;3(3):167-73

6.Kirubagaran S. Effect of fluoride Mouth Rinses Inducing Color change in Esthetic Veneer Restoration - A Spectrophotometric Analysis . Journal of Pharmaceutical Sciences and Research.2016;8(4): 210-13

7.Kim Hk, kIM SH, Lee JB, Han JS, Yeo IS. Effect of polishing and glazing on the color and spectral distributionof monolithic zirconia. The jornal of advanced prosthodontics. 2013 Aug 1;5(3):296-304.

8.Alhabdan AA, El-Hejazi AA. Comparison of Surface Roughness of Ceramics after Polishing with Different Intraoral Polishing Systems using Profilometer and SEM. J Dent Health Oral Disord Ther 2015.

9.Derafshi R, KHorshidi H, Kalantari M, Ghaffarlou I Effect of mouthrinses on color stability of monolithic zirconia and feldspathic ceramic : an in vitro study. BMC oral health 2017;17(1):129.

10..Palla ES, Kontonasaki E, Kantiranis N, Papadopoulou L, Zorba T, Paraskevopoulos KM, et.al. Color stability of lithium

disilicate ceramics after aging and immersion in comm on beverages. J Prosthet Dent. 2017 ;119(4) :632-42.

11 Hiedari M, Salari M, Hiedari M. Invitro evaluation of the effect of polishing and Glazing on the color stability 0f Ceramco II tooth porcelain on the chlorhexidine mouthwash enviroment. Researh Journal on the Dentistry Science 2016;4:95-50

$$
\begin{aligned}
& \text { محدويت هاى اين يزوهش، اثر دهانشويه ها بر سختى } \\
& \text { كاميوزيت رزين يكسان نيست. كلرهكزيدين در بين سه } \\
& \text { دهانشويه مورد يزوهش ،كمترين اثر را بر ريز سختى كاميوزيت } \\
& \text { رزين دارد، اين امر ممكن است ناشى از تفاوت PH دهانشويه } \\
& \text { هاى يروهش باشد زبه نحوى كه كلرهكَيدين PH بيشتر و } \\
& \text { محتواى الكلى كمترى نسبت به دو دهانشويه ديخر دارد. (rا) } \\
& \text { مشابهت اين مطالعه با تحقيق ما در اين است كه دهانشويه } \\
& \text { كلرهگزيدين تغيير رنگ كمترى بر مواد دارد. در مطالعهاى } \\
& \text { ديگر موضوع بررسى تاثير ڤاليش و گليز بر تغيير رنگ در } \\
& \text { يرسلن دندانى CERAMCO III در محيط دهانشويه } \\
& \text { كلرهكَيدين مشخص شد ثبات رنگ هر دو گروه يرسلن گليز و } \\
& \text { ياليش شده از نظر كلينيكى قابل قبول است و تغييرات رنت با } \\
& \text { سيستم CIElab در كروه پاليش و كليز از نظر آمارى معنى }
\end{aligned}
$$

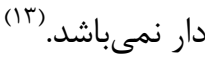

$$
\begin{aligned}
& \text { نتايج اين مطالعه از اين جهت با تحقيق ما در تضاد بود كه } \\
& \text { تغييرات رنگ در هر دو گروه مواد غوطه ور دركلرهگزيدين از } \\
& \text { لحاظ آمارى معنى دار نبودند. كه دليل ان مى تواند ناشى از } \\
& \text { تفاوت در نوع مواد مورد بررسى باشد. }
\end{aligned}
$$

نتيجه كيرى: كمترين تغيير رنگ در zirconia monolithic در محلول كلرهگزيدين و بيشترين تغييرات در سراميكهاى Ips.E max 
12 .Eeslami N, Ahrari F, Rajabi O, Zamani R. The staining effect of different mouth washes containing nanoparticles on dental enamel. J clin Exp Dent 2015;7(4):e457-61.

13. Lavaf S, et.al. Evaluation of the effect of three mouthwashes on michrohardnes of composite resin. Journal of Esfahan dental school 2011;7(1):8-13.

14. Yilmaz $C$, , Korkmaz $T$, Demirköprülü $H$, Ergün G, Ozkan Y. Color stability of glazed and polished dental porcelains. J Prosthodont. 2008;17(1): 4-20.

15.Dos Santos DM, da Silva EVF, Watanabe D, Bitencourt SB, Guiotti AM, Goiato MC. Effect of different acidic solutions on the optical behavior of lithium disilicate ceramics. J Prosthet Dent. 2017;118(3):430-36.

16. Khaledi AA, Safari A, Adibi A, Adibi S. The effect of chlorhexidine mouth rinse on color stability of porcelain with three different surface treatments: An in vitro study. J Dent Biomater 2014;1(1) 3-8.

17.Papageorgiou-kyrana A, kokoti $M$, Kontonasaki E, Koidis $P$. Evaluation of color stability of preshaded and liquid-shaded monolithic zirconia. The journal of prosthetic dentistry. $2018 ; 119(3): 467-72$.

18. Tabatabaian F. Color aspect of monolithic zirconia restorations: A review of the literature. Journal of prosthodontics. 2019;28(3): 276-87.

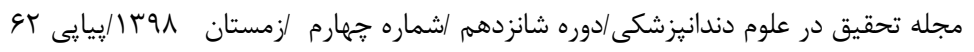

